\title{
EL HOMBRE FAULKNERIANO
}

Silvia Yfrán

\begin{abstract}
“...Vio condensar el último resplandor de luz en el cristal del reloj y transformarse la esfera, de un orificio redondo en la obscuridad, en un disco suspenso de la nada, el caos del mundo, y transformarse de nuevo en una bola de cristal que contenia en su quieta y críptica profundidad el caos ordenado del intrincado y sombrio mundo sobre cuyos flancos, cubiertos de cicatrices, las viejas heridas giran a vertiginosa velocidad al interior de la tiniebla donde asechan nuevos desastres."
\end{abstract}

Faulkner muestra, a través de sus obras, un tipo de arte que podría semejarse a lo que otros artistas han propuesto como arte abstracto: la destrucción del objeto, con el propósito de hallar lo íntimo, la esencia del objeto. Faulkner busca la destrucción del ser y de la esencia del hombre para lograr reafirmarlo ${ }^{2}$.

Abordo Sanctuary como una pintura abstracta, donde son los personajes quienes llevan en sí la mayor carga simbólica, a partir de ciertos elementos como; la constitución psicológica, el manejo del mal, la relación de los personajes entre sí y su ubicación espacio-temporal, el carácter y la conclusión con los que están determinados..

El tiempo y el espacio se conjugan en Sanctuary para otorgar a sus protagonistas un carácter clásico ${ }^{3}$. Respecto del tratamiento que le da al primero, en la novela, es lineal, permanece la sensación de un tiempo eterno donde todas las cosas ya están determinadas. Ejemplo de ello es la violación de Temple que ya está consumada desde aquel canto de la lechuza, anunciando la oscuridad y la muerte, o la metáfora, puesta ya en el principio de la obra, de un "ave de ciénaga acosada por el caimán".

El autor divide el espacio en dos escenarios simultáneos, Jefferson y Memphis, y ubica allí a sus personajes. En cada uno ellos, coloca a tres importantes figuras, en las cuales se centrará mi análisis:

En Jefferson: Ruby Lamar, Goodwin y Benbow.

En Memphis: Temple, Popeye, Red.

Estos seres psicológicamente anormales enfrentan el mal, la perversidad sexual, la muerte. Cada uno de ellos está constituido por: el cuerpo, las posibilidades morales (el mal, el bien, lo neutro), y el espíritu.

Características sexuales:

Popeye: impotente y masoquista.

Temple: ninfómana.

Ruby: prostituta.

Benbow: tendencias sexuales hacia su hijastra, incesto.

${ }^{1}$ FAULKNER, W. Sanctuary. p. 108

2 "En la técnica de Faulkner hay (...) supuestos filosóficos (...) la tragedia de la existencia refleja y realiza la tragedia de la esencia." Cambell, H.M.p.83

3 BAJTIN,M. 
Red: violencia sexual, es el segundo violador de Temple, luego de la mazorca de maíz. motivos:

El autor utiliza estas manifestaciones sexuales de una manera deliberada, por dos

a) como temática siniestra, a través de la cual, puede comenzar su destrucción del ser, enfrentando el cuerpo y la psique - de donde surgen los instintos- al espíritu de hombre;

b) para exponer la violencia del mundo moderno.

Todas las figuras mencionadas anteriormente representan a ciertos tipos sociales, que corresponden a un sector aislado de la sociedad. En la ciudad surgen otras (que no son objeto de nuestro análisis), como los Snopes, los anabaptistas, Narcissa, el fiscal.

"He aquí por qué la naturaleza es ella, y el progreso es él; la naturaleza hizo la vid, pero el progreso inventó el espejo."

Ellas son el reflejo del mundo en la conciencia de los hombres, y Popeye, a través de su perversidad, obliga al hombre a mirarse en el espejo del progreso como obligó a Temple a verse "con su pelo desgreñado y sollozando".

“...la casa era una ruina desvencijada que surgía rígida, escuálida, de un bosque de cedros por podar..."

En esa casa viven traficantes y una ex-prostituta con su hijo, son producto de la codicia y la corrupción de aquel mundo que los rechaza y que los condenará al fuego y a la muerte, por violar "las buenas costumbres". El autor los conduce o los acorrala en la ciudad, lugar al que le otorga los significados "callejón sin salida", "encierro", "cárcel".

“...Oían el rumor de la ciudad, evocativa y extraña, inminente y remota; la amenaza o la promesa a la vez; un ruido profundo y continuo sobre el cual brillaban y oscilaban luces invisibles..."

Horace huye de Kindston, cumpliendo quizá el mito del poeta que, acosado por la modernidad, intenta la vuelta a la naturaleza. Es un personaje idealista, "no puede permanecer perezosamente al margen viendo injusticias..." Pero el determinismo de su carácter clásico, no le permite la emancipación y lo único que logra es alcanzar una mayor frustración.

Popeye y Red construyen una sociedad con fines sexuales; Red es la extensión genital de Popeye, en ellos se representa el sadismo y el masoquismo, la violencia y la actitud pasiva

${ }^{4}$ Idem i.p. 21 
- pero perversa- del progreso; la acción mecánica y reiterativa, junto al hombre espectador, llevando a cabo en conjunto la destrucción ${ }^{5}$.

Temple es símbolo de los dos temas que veo en Sanctuary; la concepción del hombre faulkneriano, y la denuncia del modernismo.

Para representar al primero, enviste al personaje de connotaciones religiosas: Temple, "casa de oración", "el templo de la Antigua Alianza", que debe "ser destruido y atacado", la violan. El "Templo Santo" se ha convertido en "cueva de ladrones", Temple es aquel Santuario desvirtuado por los vendedores, sumos sacerdotes hipócritas, ladrones y asesinos que lo habitan ${ }^{6}$. El Templo será reconstruido con una Nueva Alianza, aquella que el hombre de Faulkner no ha llevado a cabo aun, pues los protagonistas se sitúan "antes de la encarnación" según Magny-; todavía no han escuchado la Buena Noticia.

En cuanto al tema del modernismo, Temple es la conciencia aprisionada del hombre, siempre encerrada, primero en una habitación de la Universidad, después en un granero, luego en un burdel.

Temple en sus sueños se transforma en niño, en maestra, en anciano, muestra el deseo del espíritu humano de metamorfosearse.

Interesantes paralelismos se dan en los personajes a través de la utilización de símbolos, por ejemplo.

- Ruby Lamar y Temple Drake se encuentran formando un paralelismo más que una contraposición. Fueron guiadas por un hombre (Goodwin, Gowan respectivamente) a "la casa". Están allí, una, protegiendo a un niño, la otra, protegiendo su virginidad, ambas son víctimas de la desesperanza. Ruby siempre en el umbral de una puerta, escondida detrás de ella, siendo testigo silencioso de los acontecimientos que suceden en la casa. Tal vez sea esta mujer- madre, símbolo de la tierra o umbral, pasaje hacia la muerte que protagonizarán todos los personajes, representación de una doble concepción filosófica: vuelta hacia la naturaleza o anhelo de la muerte.

Mientras Temple es siempre la que se oculta detrás de las puertas; según la interpretación freudiana, es símbolo de una invitación sexual ( puerta = vagina), yace encerrada tras los ruidos de los cerrojos, como símbolo de un acontecimiento sin posibilidad de rectificación. En el tiempo eterno de Faulkner la violación ya está en el pasado.

- Otro paralelismo es el de Benbow y Popeye.

"(...) el hombre que se hallaba bebiendo inclinó el rostro hacia los múltiples reflejos rotos de su propia acción de beber. Al levantarse vio entre ellos, en mil añicos, el canotier de Popeye (...)"

\footnotetext{
5 "Faulkner cree que un personaje humano se nos muestra con claridad en una situación sexual y con más claridad aún en una situación sexual anormal".

6 "La Biblia, El pueblo de Dios" (Heb. 9.1; Is. 56.7; Jer. 7.4-11; Dn. 11.31; Mat. 24.1-2)

${ }^{7}$ Idem i.p. 13
} 
Figuras antagónicas, juegan al defensor y al verdugo, arriesgando la vida de los demás. Se miraron por primera vez en el reflejo del agua, y vieron sus rostros proyectarse en mil añicos. Representan el bien y el mal respectivamente, los veo levantarse como fantasmas de la conciencia de todos los hombres, y expresar la inadecuación del ser, del hombre faulkneriano, al mundo exterior.

Tal vez la determinación de los personajes sea el resultado de la ubicación del hombre en un triple espacio; tierra, cielo e infierno. La tierra lo rechaza, hay un intento al retorno hacia la naturaleza, hacia lo primigenio, pero la naturaleza le resulta desfavorable. El cielo no existe aún como posibilidad para estos hombres; primero hay que destruir el Templo para construir la Nueva Alianza, pero los personajes de Sanctuary no han visto al Salvador. El infierno es el determinismo, la frustración, la sentencia de muerte o la parálisis de una existencia rutinaria y sin sentido.

" $\mathrm{N}$ ' hay lugar p'a ti en el sielo! ¡N' hay lugar p'a ti en el infierno! ¡N' hay lugar en la cársel de los blancos! (...) ¿a'onde vas a ir tú?"8

\section{BIBLIOGRAFIA}

BAJTIN, M., M. Estética de la creación verbal. Siglo XXI. México, 1982

CAMBELL, H. William Faulkner. Schpire. Bs. As., 1954

FAULKNER, W. Santuario. Colección Austral. Bs. As.- México, 1945

FREUD, S. Los textos fundamentales del psicoanálisis. Alianza editorial, Madrid- Bs. As., 1988

HOFFMAN. F. William Faulkner. CGF editora. Bs. As., 1963

8 Idem i .p. 91 